Supporting Information

\title{
Nanoporous PVDF Hollow Fiber Employed Piezo-tribo Nanogenerator for Effective Acoustic Harvesting
}

Zhaohan Yu ${ }^{1}$, Ming Chen ${ }^{1}$, Yunming Wangl *, Jiaqi Zheng ${ }^{1}$, Yongkang Zhang ${ }^{2}$, Huamin Zhou ${ }^{1}$, Dequn $\mathrm{Li}^{1}$

1. State Key Laboratory of Materials Processing and Die \& Mould Technology, School

of Materials Science and Engineering, Huazhong University of Science and Technology, Wuhan 430074, China.

2. School of Mechanical and Electronic Engineering, Jingdezhen Ceramic Institute, Jingdezhen, 333403, PR China.

E-mail addresses: wang653@hust.edu.cn (Y. Wang). 
SEM images of pure PVDF, PVDF/PEG, PH, PHV fiber: To clearly illustrate the formation process of the nanoporous PVDF hollow fiber with PDMS valve (PHV) membrane, the morphology of pure PVDF fiber, PVDF/PEG coaxial fiber, nanoporous PVDF hollow fiber (PH fiber) and PHV fiber are characterized in Figure S1.

a

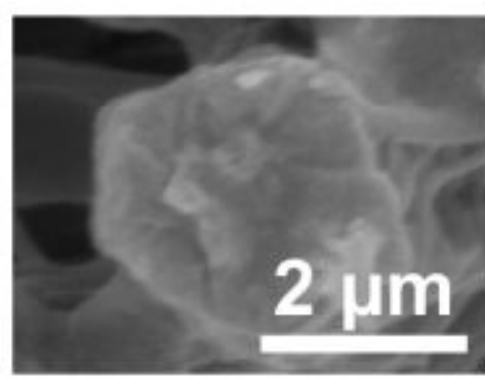

C

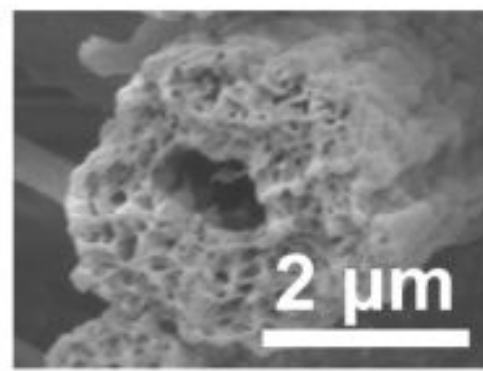

b

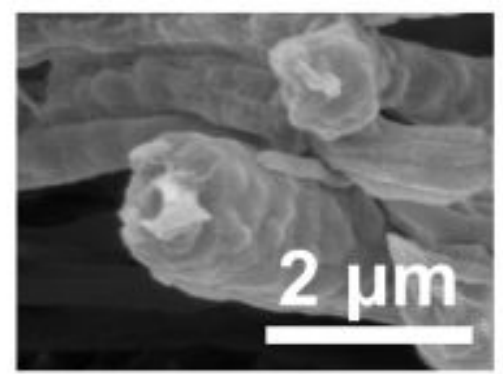

d

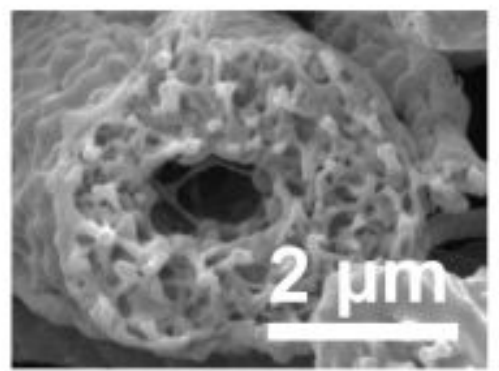

Figure S1. Morphology of (a) pure PVDF fiber, (b) PVDF-PEG coaxial fiber, (c) nanoporous PVDF hollow fiber and (d) nanoporous PVDF hollow fiber with PDMS valve.

The influence of different concentrations of PVDF: Different concentrations of PVDF solution are employed for the forming of PHV membrane to explore the optimal concentration. As shown in Figure S2, within the range of $14 \%$ to $16 \% \mathrm{w} / \mathrm{v}$, PVDF nanofibers display a smooth and uniform morphology. Lower concentrations will lead 
to rupture of the polymer fibers before they reach the collector, resulting in the formation of beads or beaded fibers as shown in Figure S2a and b. However, higher concentrations increase the viscosity of the solution and hinder its flow, which also results in defective nanofibers (Figure S2e).

a

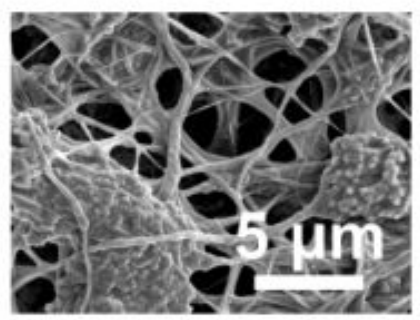

d

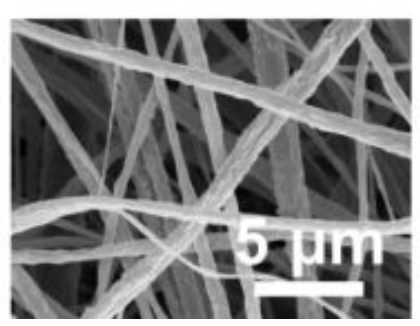

b

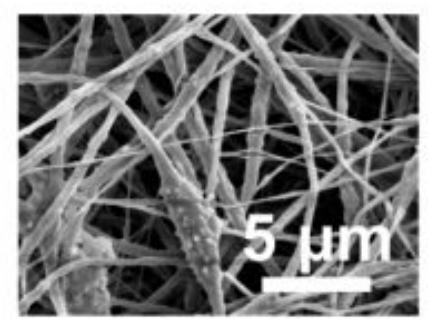

e

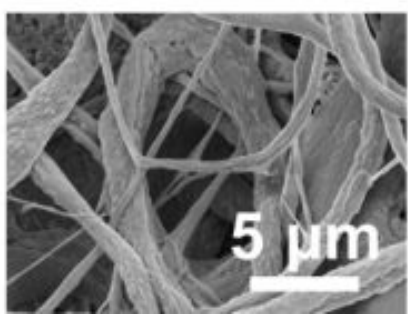

C

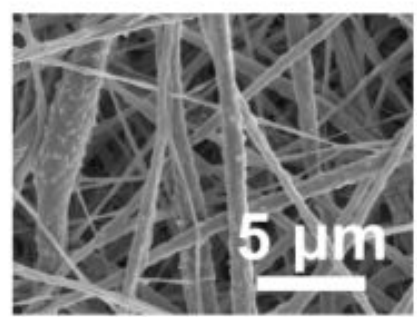

Figure S2. Surface morphology of membrane with different concentration of PVDF at (a) $10 \%$, (b) $12 \%$, (c) $14 \%$, (d) $16 \%$ and (e) $18 \%$.

FTIR analysis: FTIR tests were performed on the samples before and after etching to analyze the presence of PEG (Figure S3). The bands representing PEG at $946 \mathrm{~cm}^{-1}$, $2873 \mathrm{~cm}^{-1}$ and $3452 \mathrm{~cm}^{-1}$ appeared in the PVDF/PEG fiber but disappeared in the nanoporous PVDF hollow fiber membrane proves that PEG was successfully doped during electrospinning and completely removed after etching, which verified the feasibility of this method. 


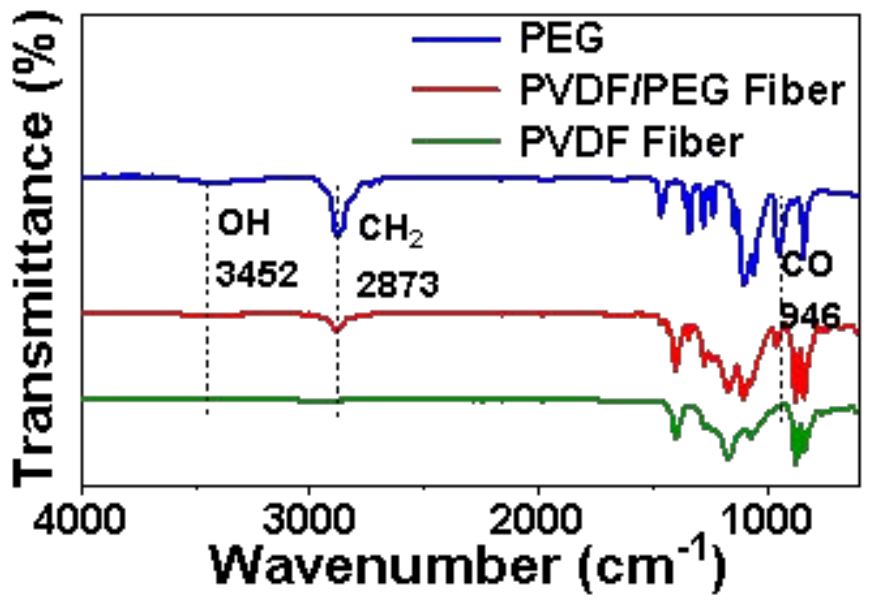

Figure S3. FTIR image of PEG, PVDF/PEG coaxial fiber and nanoporous PVDF hollow fiber.

The influence of different concentrations of PEG: PEG is introduced here to occupy the core channel during the forming process and is subsequently etched and removed to obtain porous and hollow nanofibers. The morphology of nanoporous hollow fibers made from different concentrations of PEG are observed (Figure S4). 
a

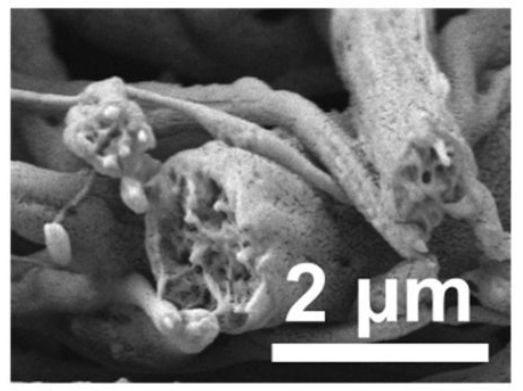

C

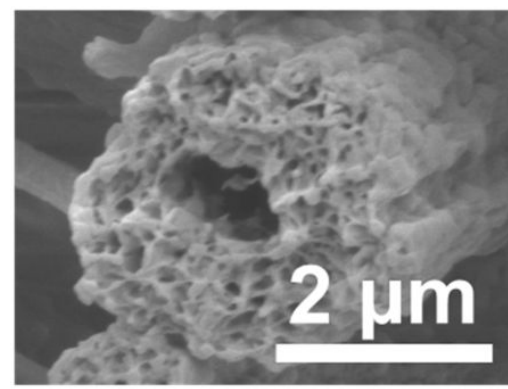

b

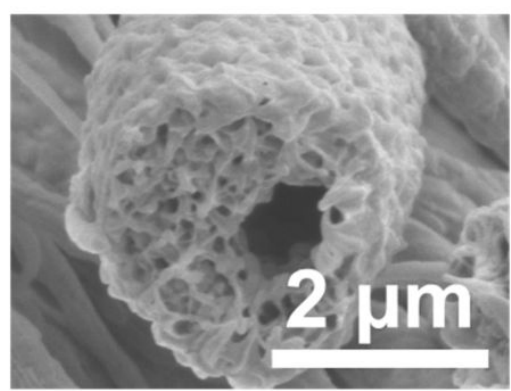

d

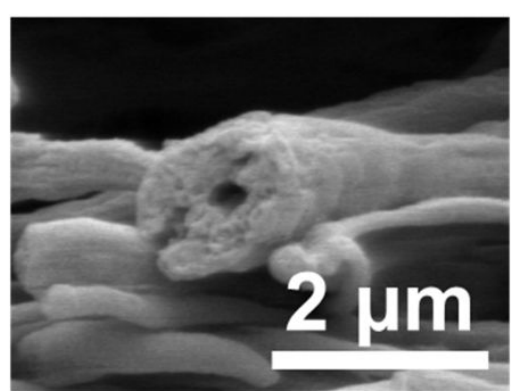

Figure S4. Morphology of PVDF porous hollow fibers fabricated with different concentrations of PEG (a) 20\%, (b) $25 \%$, (c) $30 \%$ and (d) $35 \% \mathrm{w} / \mathrm{v}$.

The influence of different concentrations of PDMS: The doping of diluted PDMS solution can introduce valve structure in the fibers. The morphology of the PVDF porous hollow fiber with PDMS valve and the output current corresponding to different concentrations of PDMS are shown in Figure S5. 
a

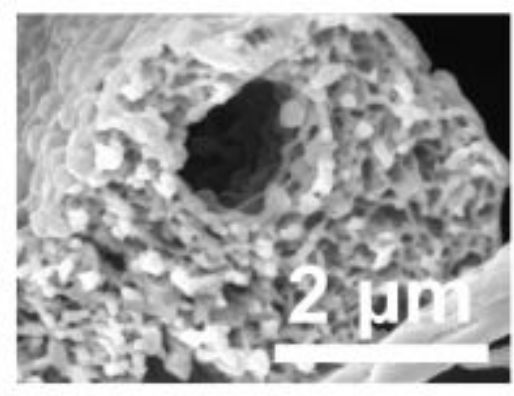

C

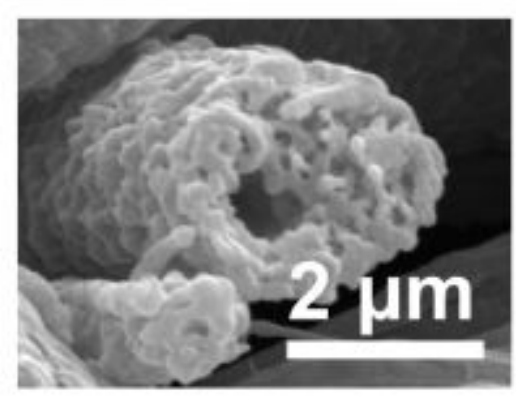

b
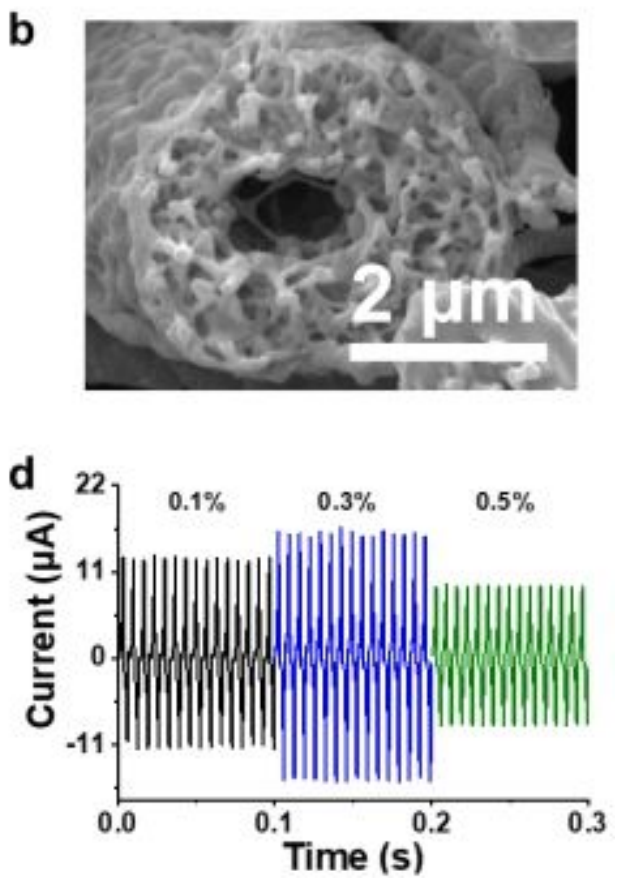

Figure S5. Morphology of nanoporous PVDF hollow fibers with PDMS valve fabricated with diluted PDMS at the concentration of (a) $0.1 \%$, (b) $0.3 \%$ and (c) $0.5 \%$ w/v; (d) Output current of PHVAH fabricated with different concentrations of PDMS.

Calculation of sound pressure: Sound pressure caused by the presence of sound waves will cause vibration and deformation of the PHPV membrane. The relationship between sound pressure (P) and Sound Pressure Level (SPL) can be converted by

$$
\mathrm{SPL}=20 \lg \frac{P}{P_{0}}
$$

where $\mathrm{P}_{0}$ represents the reference sound pressure level and the value is $2 \times 10^{-5} \mathrm{~Pa}$. Thus, the actual sound pressure applied on the PHPV membrane can be calculated. 
SPL measurements: The directional dependence pattern of the PHVAH has been evaluated by rotating the device. As illustrated in Figure S6, the detected SPL decreases from $117.6 \mathrm{~dB}$ to $91.7 \mathrm{~dB}$ as the PHVAH rotates from $0^{\circ}$ to $180^{\circ}$, which corresponds to a drop in voltage from $105.5 \mathrm{~V}$ to $2.9 \mathrm{~V}$. Then from $180^{\circ}$ to $360^{\circ}$, the measured SPL and voltage gradually rise back. When the sound comes from the direction facing the PHVAH $\left(0^{\circ}\right)$, the sound pressure received by the device is the largest $(117.6 \mathrm{~dB})$, which will produce the largest electrical output $(105.5 \mathrm{~V})$. Moreover, the PHVAH is more sensitive to the sound coming from directions with an angle from $-30^{\circ}$ to $30^{\circ}$, corresponding to a received sound pressure higher than $108.4 \mathrm{~dB}$ and an output voltage higher than $20 \mathrm{~V}$, while it is less sensitive to the contributions from other angles. And experimental results indicate that the change of sound frequency has negligible influence on the measured SPL.
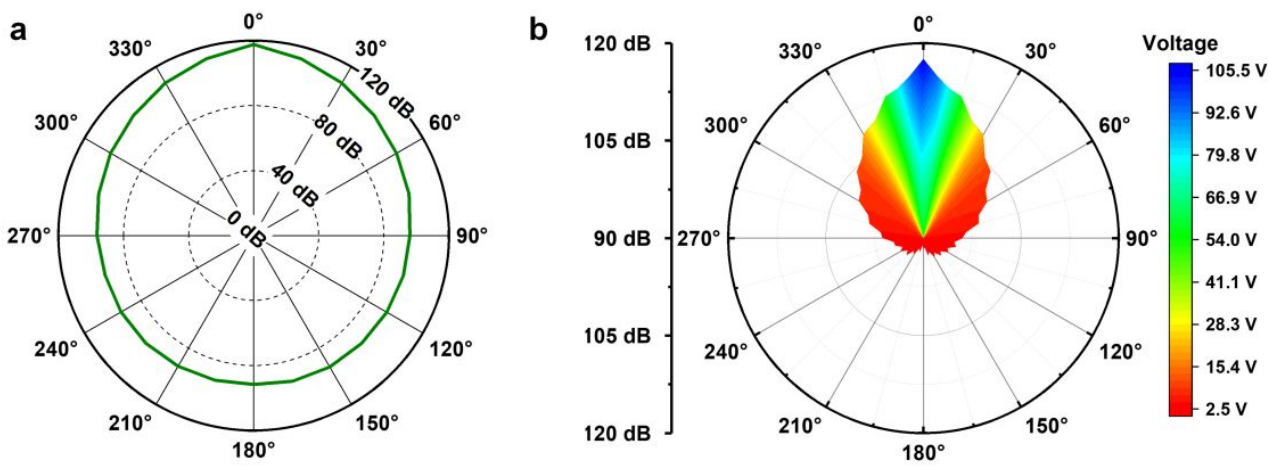

Figure S6. (a) SPL polar plots at different angles from $0^{\circ}$ to $360^{\circ}$; (b) The detected SPL and output voltage of PHVAH at different angles. 
Durability and stability: To evaluate the durability and cycle stability of PHVAH, its performance has been tested repeatedly. As shown in Figure S7, after $1 \mathrm{~h}, 2 \mathrm{~h}$ and $4 \mathrm{~h}$ of continuous stimulation, the corresponding output voltages are $103.2 \mathrm{~V}, 104.3 \mathrm{~V}$ and 105.5 V, respectively. The stable performance of PHVAH working at a frequency above $100 \mathrm{~Hz}$ within 4 hours, corresponding to over 1,440,000 cycles, together with the durability verified by repeated tests within a week, greatly demonstrates its practical application value.

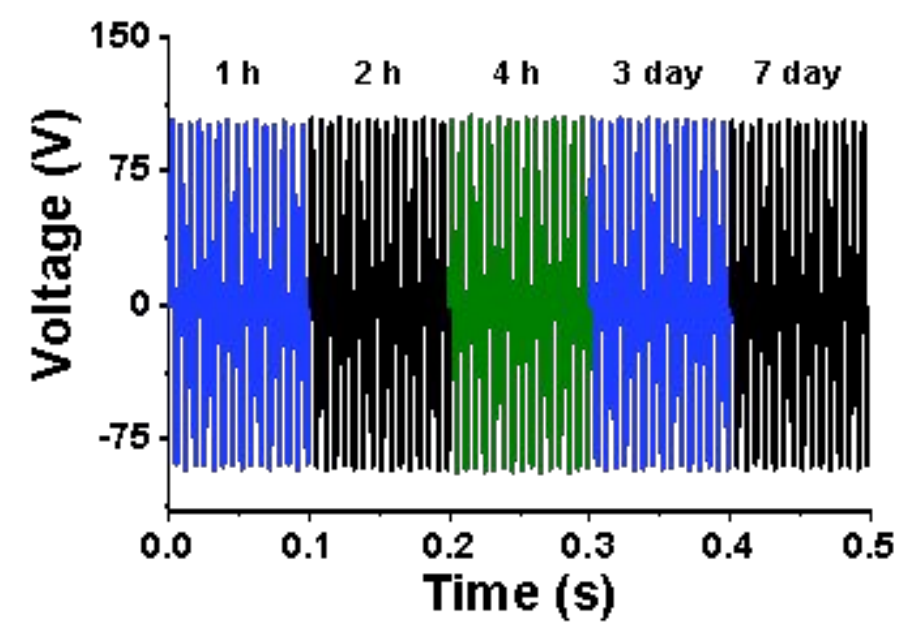

Figure S7. Output voltage of PHVAH within 7 days.

Images of PHVAH device: Figure S8 shows the structure illustration and physical photos of the fabricated PHVAH device. 
a

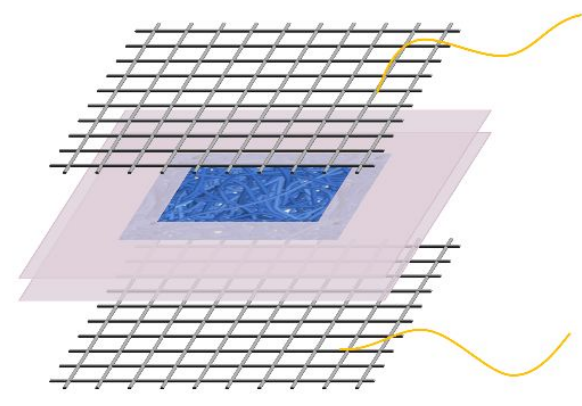

b

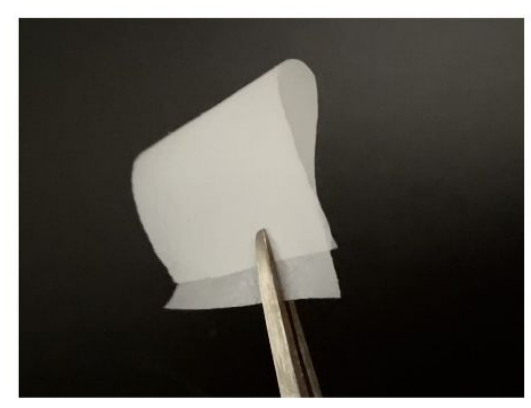

Iron mesh

PI film

PHV membrane

PI film

Iron mesh

Wire

\section{C}

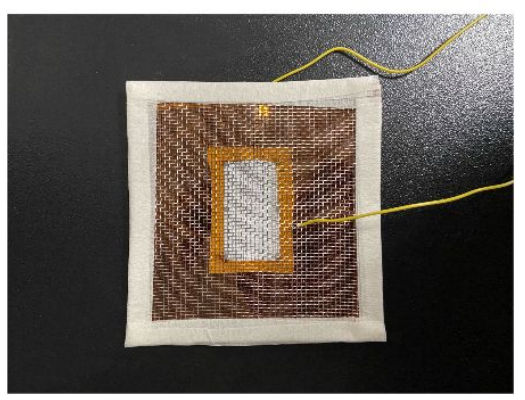

Figure S8. (a) Structure illustration of PHVAH; (b)The photograph of PHV membrane;

(c) The photograph of PHVAH device.

Table S1. Summary of the PENG perfomance in the literature

\begin{tabular}{cccccccc}
\hline Materials & $\begin{array}{c}\text { Device size } \\
\left(\mathrm{cm}^{3}\right)\end{array}$ & $\begin{array}{c}\text { SPL } \\
(\mathrm{dB})\end{array}$ & $\begin{array}{c}\text { Frequency } \\
(\mathrm{Hz})\end{array}$ & $\begin{array}{c}\text { Voltage } \\
(\mathrm{V})\end{array}$ & $\begin{array}{c}\text { Load resistance } \\
(\mathrm{k} \Omega)\end{array}$ & $\begin{array}{c}\text { Power output } \\
\text { density }\end{array}$ & Reference \\
\hline PZT & 3972.22 & 100 & $170-206$ & - & 38 & $0.034-0.36 \mathrm{~W} \mathrm{~m}^{-3}$ & 1 \\
PVDF/ZnO & 0.036 & 116 & 140 & 1.12 & 700 & $0.02 \mathrm{~W} \mathrm{~m}-^{2}$ & 2 \\
PVDF-TrFE & 0.024 & 115 & 210 & 14.5 & 470 & $0.118 \mathrm{~W} \mathrm{~m}^{-2}$ & 3 \\
PZT & 251 & 100 & 175 & 0.283 & 11 & $0.029 \mathrm{~W} \mathrm{~m}^{-3}$ & 4 \\
PAN & 0.036 & 117 & 230 & 58 & 4000 & $0.1753 \mathrm{~W} \mathrm{~m}^{-2}$ & 5 \\
PVDF/PDMS & 0.182 & 117 & 170 & 105.5 & $10^{4}$ & $0.92 \mathrm{~W} \mathrm{~m}^{-2}$ & This work \\
\hline
\end{tabular}

Table S2. Summary of the TENG perfomance in the literature

\begin{tabular}{ccccccccc}
\hline Materials & $\begin{array}{c}\text { Device } \\
\text { size }\left(\mathrm{cm}^{3}\right)\end{array}$ & $\begin{array}{c}\text { Struc } \\
\text { ture }\end{array}$ & $\begin{array}{c}\text { SPL } \\
(\mathrm{dB})\end{array}$ & $\begin{array}{c}\text { Frequency } \\
(\mathrm{Hz})\end{array}$ & $\begin{array}{c}\text { Voltag } \\
\mathrm{e}(\mathrm{V})\end{array}$ & $\begin{array}{c}\text { Load resistance } \\
(\mathrm{k} \Omega)\end{array}$ & $\begin{array}{c}\text { Power output } \\
\text { density }\end{array}$ & Reference \\
\hline PTFE/Al & 570 & {$[\mathrm{a}]$} & 110 & 240 & 60.5 & $6 \times 10^{3}$ & $0.0602 \mathrm{~W} \mathrm{~m}^{-2}$ & 6 \\
PDMS/CNTs & 6.9 & {$[\mathrm{~b}]$} & - & 4240 & 0.22 & $10^{3}$ & $4 \times 10^{-6} \mathrm{~W} \mathrm{~m}^{-2}$ & 7 \\
PVDF/PE & 0.5 & {$[\mathrm{c}]$} & 100 & 175 & 90 & 0.1 & $0.202 \mathrm{~W} \mathrm{~m}^{-2}$ & 8 \\
PVDF/PDMS & 0.182 & {$[\mathrm{~d}]$} & 117 & 170 & 105.5 & $10^{4}$ & $0.92 \mathrm{~W} \mathrm{~m}^{-2}$ & This work \\
\hline
\end{tabular}


[a] Relying on a Helmholtz cavity with a size-tunable narrow neck on its back.

[b] Relying on a 1-D phononic crystal consisting of five steel slabs standing in air medium.

[c] Employing a simple sandwich structure.

[d] Employing a simple sandwich structure while exhibiting competitive performance.

Table S3. Sound pressure level of various sound sources. ${ }^{9}$

\begin{tabular}{cc}
\hline Sound energy source & Sound pressure level (dB) \\
\hline Auditory threshold at 1 kHz & 0 \\
Rustling of leaves & 20 \\
Quiet room & 40 \\
Normal conversation & 60 \\
Central city & 70 \\
Traffic on a busy road & 86 \\
Motorcycle starting & 95 \\
Decoration electric drill & 100 \\
Karaoke & $110-120$ \\
Takeoff of the plane & 125 \\
Firecrackers & $125-155$ \\
1 m from jet engine & 150 \\
\hline
\end{tabular}

\section{Supplementary Video S1:}

The electrical signal response of PHVAH when playing a piece of music.

\section{Supplementary Video S2:}

7 blue LED bulbs connected in series into a ' $\mathrm{V}$ ' shape are illuminated directly by the PHVAH. 


\section{Supplementary Video S3:}

The LED bulbs powered by the PHVAH flickers along with the rhythm of the audio.

\section{REFERENCES}

(1) Yang, A.; Li, P.; Wen, Y.; Lu, C.; Peng, X.; He, W.; Zhang, J.; Wang, D.; Yang, F. Note: High-efficiency broadband acoustic energy harvesting using Helmholtz resonator and dual piezoelectric cantilever beams. Rev Sci Instrum 2014, 85 (6), 066103.

(2) Sun, B.; Li, X.; Zhao, R.; Ji, H.; Qiu, J.; Zhang, N.; He, D.; Wang, C. Electrospun poly(vinylidene fluoride)-zinc oxide hierarchical composite fiber membrane as piezoelectric acoustoelectric nanogenerator. Journal of Materials Science 2018, 54 (3), $2754-2762$.

(3) Lang, C.; Fang, J.; Shao, H.; Wang, H.; Yan, G.; Ding, X.; Lin, T. High-output acoustoelectric power generators from poly(vinylidenefluoride-co-trifluoroethylene) electrospun nano-nonwovens. Nano Energy 2017, 35, 146-153.

(4) Yuan, M.; Cao, Z.; Luo, J.; Pang, Z. Helix structure for low frequency acoustic energy harvesting. Rev Sci Instrum 2018, 89 (5), 055002.

(5) Shao, H.; Wang, H.; Cao, Y.; Ding, X.; Fang, J.; Niu, H.; Wang, W.; Lang, C.; Lin, T. Efficient conversion of sound noise into electric energy using electrospun polyacrylonitrile membranes. Nano Energy 2020, 75, 104956.

(6) Yang, J.; Chen, J.; Liu, Y.; Yang, W.; Su, Y.; Wang, Z. L. Triboelectrificationbased organic film nanogenerator for acoustic energy harvesting and self-powered active acoustic sensing. Acs Nano 2014, 8 (3), 2649-57.

(7) Javadi, M.; Heidari, A.; Darbari, S. Realization of enhanced sound-driven CNTbased triboelectric nanogenerator, utilizing sonic array configuration. Current Applied Physics 2018, 18 (4), 361-368.

(8) Cui, N.; Gu, L.; Liu, J.; Bai, S.; Qiu, J.; Fu, J.; Kou, X.; Liu, H.; Qin, Y.; Wang, Z.

L. High performance sound driven triboelectric nanogenerator for harvesting noise 
energy. Nano Energy 2015, 15, 321-328.

(9) Choi, J.; Jung, I.; Kang, C.-Y. A brief review of sound energy harvesting. Nano Energy 2019, 56, 169-183. 